\title{
Enumeration of ethno-medicinal plants in Rongram Block of West Garo Hills District, Meghalaya
}

\author{
Naldarine M. Marak, ${ }^{*}$ Lalnundanga \\ Department of Forestry, Mizoram University, Tanhril 796004, India
}

\begin{abstract}
A study was conducted to enumerate the ethno-medicinal plants in Rongram block of West Garo Hills District, Meghalaya. The study was based on the primary survey and data collected through questionnaires, focus-group discussions and semi-structured interviews prepared for the purpose by approaching the local traditional healers (oja) as well as villagers. The study revealed that a total of 18 medicinal plants belonging to 18 genera and 16 families were documented. Information on local names, scientific names, family, plant parts used and traditional usage of these plants were also reported. Among the documented medicinal plant species, trees were most frequently used followed by herbs, shrubs and climbers. The study also revealed that leaves were most commonly used in the treatment followed by the bark.
\end{abstract}

Key words: Ethnomedicine; Oja; Rongram block; West Garo Hills

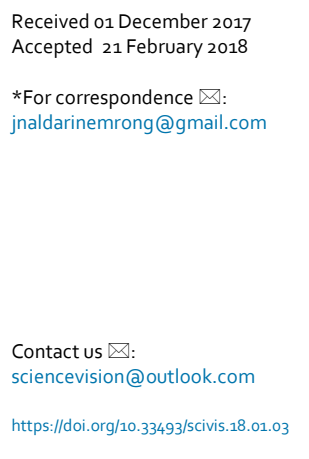

Received o1 December 2017

*For correspondence $\bowtie$ : jnaldarinemrong@gmail.com

Contact us $\square$ : https://doi.org/10.33493/scivis.18.01.03

\section{Introduction}

The survey on ethno-botanical knowledge possess as a part of living cultural knowledge and practice between the communities before the traditional cultures are exploited by modern societies. Ethno-medicines and medicinal plants of Meghalaya have received some attention of researcher. ${ }^{1,2}$ Search for new medicines for the prevention and cure of deadly diseases provides prospects for developing medicinal plants. It therefore, behoves us to push forward, along with ethno-botanical investigation, studies on the flora in general. ${ }^{3-6}$

Meghalaya is regarded "the abode of clouds" situated in the north-eastern Himalayan region of India. Geographically, it is located between $20.1^{\circ} \mathrm{N}$ and $26.5^{\circ} \mathrm{N}$ latitude and $85.49^{\circ} \mathrm{E}$ and $92.52 \mathrm{E}^{\circ}$ longitude and covers an area of about
22,429 square kilometres.

There are limited studies on the different aspects of medicinal plants and their role in West Garo Hills District of Meghalaya. The purpose of the study was not only the collection of first-hand information about the relationship of medicinal plants with the community but also to verify the already published data wherever possible Therefore, the present study has taken up to identify the common medicinal plants growing in this area, their practices and pattern of utilization by the people in West Garo Hills District.

\section{Materials and Methods}

\section{Study Area}

A survey was conducted in Rongram Devel- 


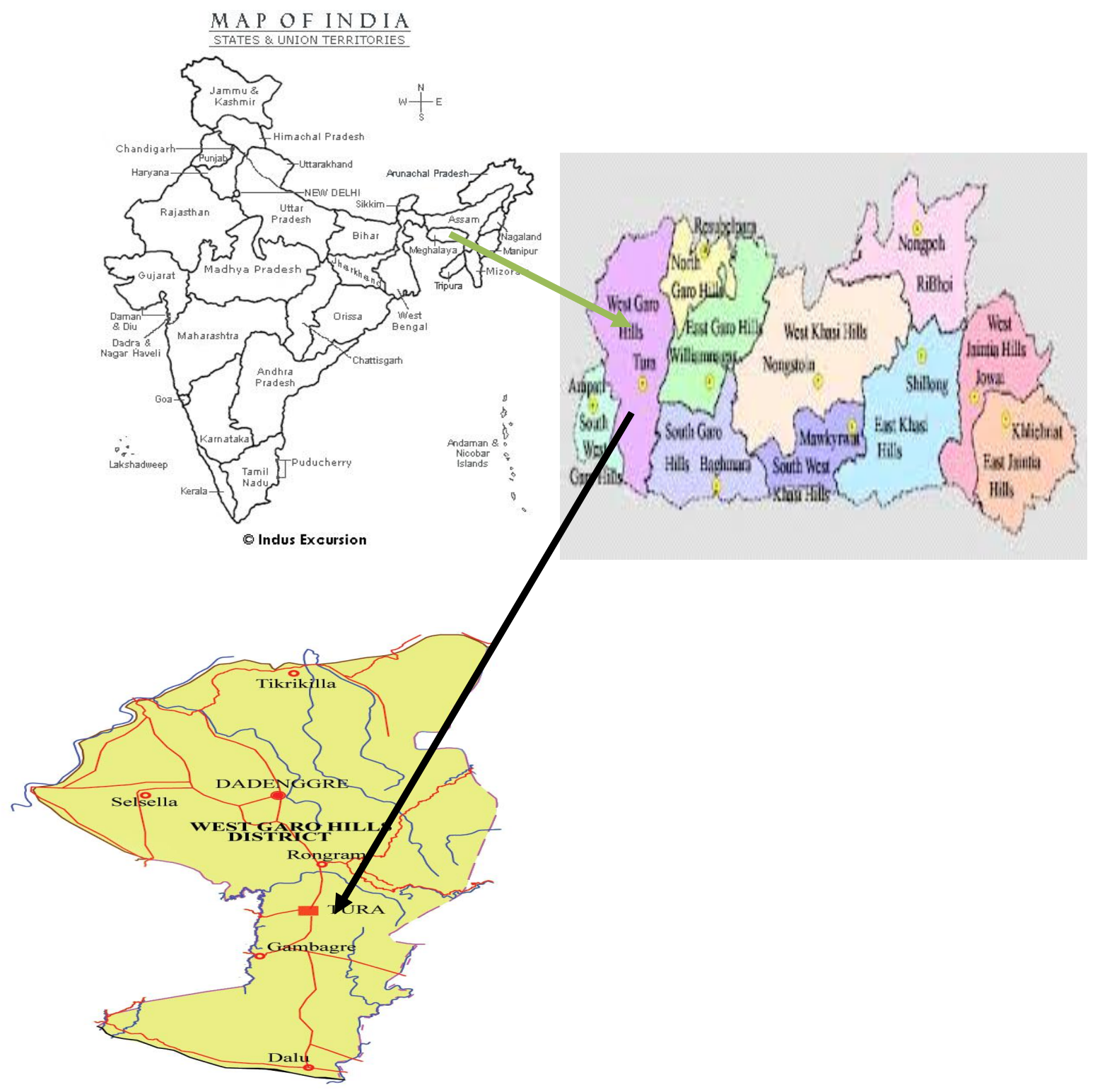

Figure 1 | Map of West Garo Hills District.

opmental Block which is administered by the West Garo Hills District Meghalaya. It is situated approximately between the latitudes $90^{\circ} 30^{\prime}$ and $89^{\circ} 40^{\prime} \mathrm{E}$, and the longitudes of $26^{\circ}$ and $25^{\circ} 20^{\prime} \mathrm{N}$ and has an area of 3,677 sq. km. West Garo Hills district is essentially a hilly and tribal area and as per 2011 census (provisional), the population of the district is $6,42,923$ with male population of
$3,24,900$ and female population of $3,18,023$. The population is pre-dominantly inhabited by the Garo people, a tribe with a matrilineal society. The district is mostly hilly with plains fringing the northern, western and south-western borders. The climate of the district is largely controlled by south-west monsoon and seasonal winds. The district being relatively lower in alti- 
Sci Vis 18 (1), 16-21 (2018)

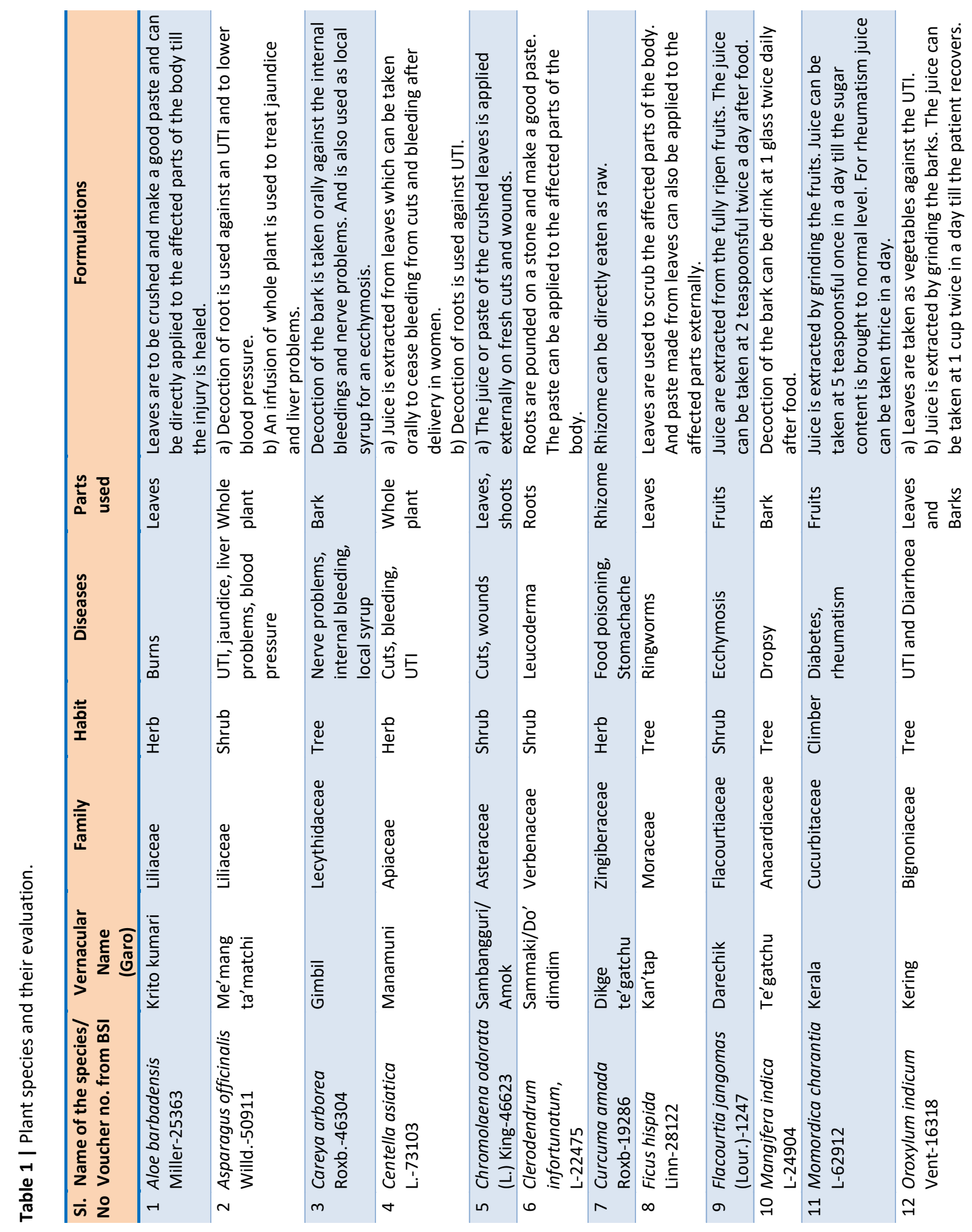




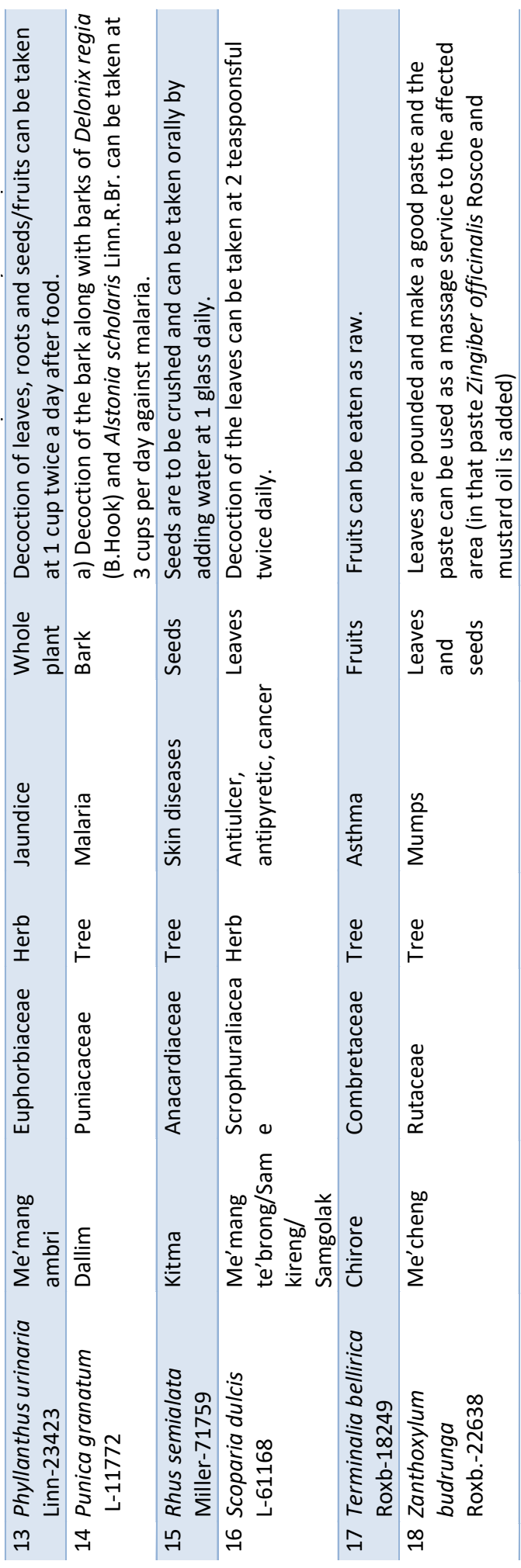

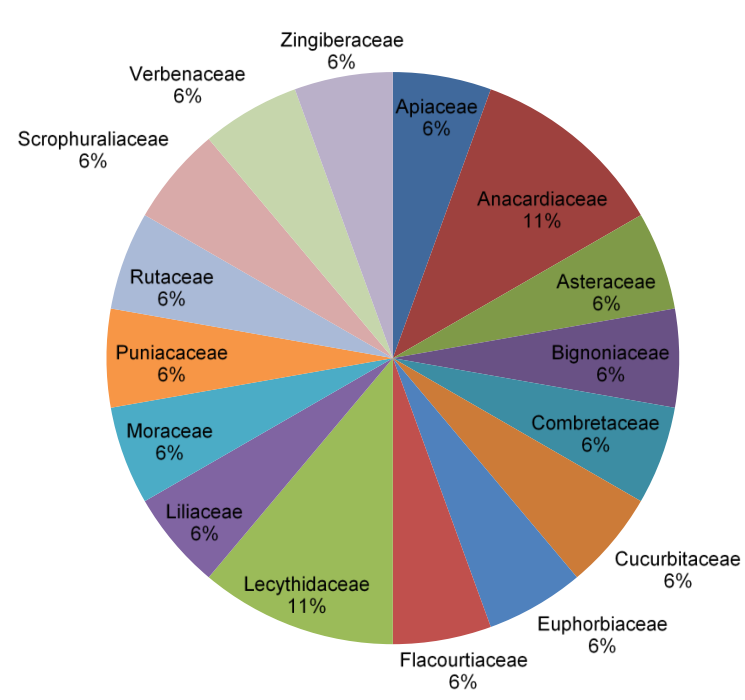

Figure $\mathbf{2}$ | Family-wise species arrangement of plant species in percentage (\%).

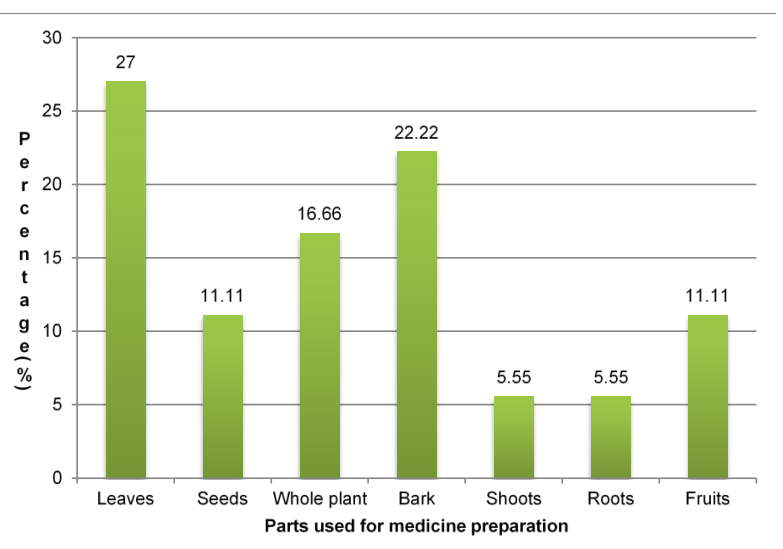

Figure 3 | Bar diagram showing plant parts used for various ailments.

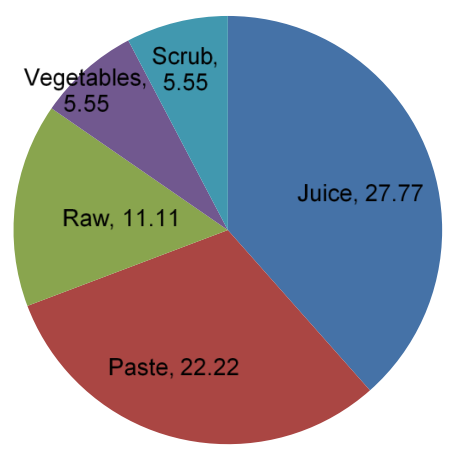

Figure 4 | Showing mode of application of ethnomedicinal plants (\%). 
tude to the rest of Meghalaya, experiencing fairly high temperature for most part of the year. The average rainfall is $330 \mathrm{~cm}$ of which more than two-thirds occur during the monsoon, winter being practically dry. The district has mostly dense tropical mixed forest, and a small patch of temperate forest in the higher parts of the Tura range.

\section{Methodology}

Preliminary survey and data were collected during 2014-2016 by filling up the questionnaire, personal interviews with the real practitioners or oja, knowledgeable persons of men, women and young folks who use their knowledge of medicinal plants. A total of 15 individuals from 14 villages were interviewed who were identified with the help of local administrators and community leaders. The collected specimens were identified with the help of literature and by using various floras and monographs including regional flora and the data collected were compared and cross checked with other recommended literature. ' Collected specimens were identified with the help of Botanical Survey of India, shillong (voucher numbers are given in the Table 1 followed by botanical name of each species)

\section{Results}

A total of 18 medicinal plant species belonging to 18 genera and 16 families, which are used in the treatment of different diseases have been documented. The study based on the plant parts used had revealed that leaves $(27 \%)$ were most commonly used in the treatment like cancer, antiulcer, antipyretic, skin diseases, urinary tract infection, burns, cuts and wounds, followed by bark (22.22\%), whole plant (16.66\%), fruits and seeds (11.11\%), shoots and roots (5.55\%). In the study, trees ( 8 species) were recorded to have highly used potential followed by herbs (5 species) which can cure extensive range of diseases. The survey also found out that some plants such as Asparagus officinalis Willd., Careya arborea Roxb., Scoparia dulcis L., has one or more ethno-medicinal uses. In terms of medicinal preparations, people mostly used by decoction (38.88\%) and followed by juice (27\%), paste $(22.22 \%)$, raw and infusion $(11.11 \%)$, as vegetables and scrub (5.55\%). Traditional healers recommended dosage of a particular recipe differently and also on the severity of the ailment and with the patients age. Dosages were estimated using the spoon, cups, glasses and the frequency of treatment depended on the disease and level of its severity

\section{Discussion}

This data is the first hand information of ethno-medicinal plants from Rongram Developmental Block of West Garo Hills District Meghalaya. The healers claimed that their herbal remedies have a high potential to cure different diseases. And also sometimes the local healers used combination with other plants and in such cases, the study emphasized to scientific validation of the reported species through phytochemical analysis as the information given by the practitioners may not always be a reliable one. It was also explored that some of the traditional healers have developed their own herbal garden for use of these fresh drugs for treatment. The study also brought to light that some of the traditional healers or oja often do not want to disclose their knowledge fully though they have rich accumulation of knowledge on medicinal plants. This may be because of their lack of education or unaware of preservation of traditional knowledge system. Since the ethnobotanical information is declining day by day and with generations, so it is a high time to strengthen and document and also to evaluate this traditional information before they are completely lost.

\section{References}

I. Rao, M.K.V. \& Shampru, R. (198I). Some plants in the life of the Garos of Meghalaya. In: Glimpses of India Etbnobotany, (eds), S.K. Jain. Oxford \& IBH Publishing Co, New Delhi, pp.I53-ı6o.

2. Dolui, A.K., Sharma,H.K., Marien,T.B. \& Lalruat- 
puii,T.C. (2004). Folk herbal remedies from Meghalaya. Journal of Traditional Knowledge 3, 358-364.

3. Schultz, R.E. (1962). The role of Ethnobotanists in Search for Medicinal Plants. Lloydia 25, pp. 257-266.

4. Lalnundanga, Sahoo, U.K., Jha, L.K. \& Lalthantluanga, R. (1997). Ethnobotanical flora in the humid subtropical semi-evergreen forest of Mizoram. In: Health Care and Development of Herbal Medicines (eds) Puri. Department of Botany, IGAU, Raipur, pp. 46-47.
5. Lalnundanga (2000). Study of Medicinal Plants in Tropical and Sub-tropical semi-evergreen Forest of Mizoram (Ph. D. Thesis, MZU, Mizoram), pp. I-I79.

6. Lalramnghinglova, H. \& Jha, L.K. (1999). New Records of ethnomedicinal plants from Mizoram. Ethnobotany II, 57-64.

7. Sharma, B.D, Balakrishnan, N.P, Rao, R.P \& Hajra, P.K. (1993). Flora of India, Volume I-III. Botanical Survey of India, Calcutta, Deep Printers, New Delhi. 